\title{
Analysis of access to the electricity transmission network using information technologies in some countries
}

\author{
Gulmira Azieva ${ }^{1}$, Seyit Kerimkhulle ${ }^{1}$, Umut Turusbekova ${ }^{2}$, Ainagul Alimagambetova ${ }^{2}$, and \\ Shakizada Niyazbekova ${ }^{3, *}$ \\ ${ }^{1}$ L.N. Gumilyov Eurasian National University, 1, Satpaev str., 010000, Nur-Sultan, Kazakhstan \\ ${ }^{2}$ Kazakh University of Economics, Finance and International Trade, 1, Satpaev str., 010000, Nur- \\ Sultan, Kazakhstan \\ ${ }^{3}$ Moscow Witte University, 12 stroenie 1, 2-I Kozhuhovski proezd, 119454, Moscow, Russia
}

\begin{abstract}
The role of information technology is especially great in strategic sectors of the economy, one of which is energy. After all, the more complex the product, the more acutely it needs more automation of the processes taking place in it. The main informational tasks of power generation are the automation of technological process systems and control over the installed equipment. The main factor that influences the development of information technologies in the energy sector in Kazakhstan is the need for high-tech reforms in this sector of the economy. Thus, the development of IT technologies in the energy sector, like any other industry, will lead to the automation of the entire complex, which will entail its more efficient operation in every sense. The article provides an overview of works devoted to the problem of access to the electricity transmission network in Africa, India, Turkey, etc.
\end{abstract}

\section{Introduction}

According to experts in the field of the electric power industry, the development of this industry currently has a number of serious problems, which excludes the efficient operation of all-electric power processes. All generating equipment has been subject to aging and wear and tear.

This can lead to technological failures, accidents. The use of the most advanced technologies by power generating companies can improve performance, ensure the stability of processes and equipment, and increase generating capacity.

The electric power industry is one of the most important infrastructural sectors of the economy. Its problems have a negative impact on the development of the country's economy as a whole.

\footnotetext{
*Corresponding author: shakizada.niyazbekova@gmail.com
} 


\section{Methods}

While writing this article, analysing the work of foreign scientists, we realized that the main factor influencing the development of information technologies in the energy sector of Kazakhstan is the economy. The work uses the rules of classical theory, the rules of the basic concepts of information technology.

\section{Results}

Energy and its efficient use have become an important factor in the survival and development of civilization, and recently have become a key modern indicator of the nation's well-being.

The particular importance of meeting the energy needs of modern civilization is one of the most important elements of national security. In particular, along with military, economic, environmental, food and other types of security, characteristics such as energy security are reflected in our daily life.

For example, there is a linear relationship between the specific volume of energy consumption per kWh of electricity consumed per capita per year in a given country, which is a human development index - a quantitative description of the situation in the country where it is introduced. (The detection rate is about 0.85 ).

The Human Development Index takes into account three main parameters:

- human life expectancy;

- education of the adult population and coverage of three levels of education - primary, secondary and higher;

- Standard of living as measured by real GDP per capita.

The US national energy priorities are articulated in the New Energy Policy, the EU energy security strategy is listed in the Green Paper, and Japan's energy strategy is based on 3E: Energy Security - Energy Security, Energy Efficiency - Energy Efficiency and Environmental Security.

Today and for a long time, the only problem associated with the depletion of basic energy resources is the fact that more than $80 \%$ of electricity is generated over time due to:

- a sharp increase in population, as well as an increase in energy consumption per capita, which led to an increase in total energy consumption, Figure 1;

- depletion of mineral and energy resources suitable for the development of deposits;

The development of complex deposits places a heavy burden on consumers - ecomineral energy resources;

The development of complex deposits places a heavy burden on consumers - the economy and the social sphere.

Experts say that one of the biggest problems determining the present and future of earthly civilization is the lack of available energy resources and dangerous anthropogenic changes in the environment.

This includes the need for new materials and the population explosion in underdeveloped countries.

\section{Discussion}

In article, the authors drew attention to three environmental impacts that have a particular impact on the age group of the population - carbon emissions from energy and electricity consumption in the residential sector, as well as total carbon emissions for a group of developed countries and received STIRPAT results as a starting point. They showed a 
further distribution of the population into three key age groups: 20-34, 35-49, and 50-64, and thus proving that environmental impacts differ significantly in different age groups, with older age groups (those that usually associated with larger households) actually have a negative impact. In addition, the authors believe that urbanization in developed countries best measures access to a country's energy system and is thus positively associated with residential energy consumption [1].

Sub-Saharan Africa (SSA) was recently ranked as the worst in the world in terms of access to electricity, according to the author of published in 2016. In a region with a population of over 936.1 million, $48 \%$ of the total population does not have access to electricity. This, in turn, serves as proof that the energy sector in the region is far below expectations. Thus, the fulfillment of regional and African economic and social obligations depends on the ability of the government and the private sector to develop electricity, as there is potential for energy production in the region. It should be noted that there are more than ten types of potential energy supply. In fact, over the past two decades, SSA countries have implemented large-scale power sector reforms that have attracted private sector investment and increased fuel supply for power generation [2].

One area that has received significant attention is electricity pricing, which is a critical mechanism for improving the efficiency and stability of the energy sector. The study [1] examined the impact of recent electricity pricing reforms on electricity performance in subSaharan Africa. The correlation design of the studies was used in 27 sub-Saharan countries for five years (2009-2013).

In article [3], the author analyzes the decision of the European Court of Justice regarding direct access to electricity transmission networks by Julius Sabatauskas and other direct access to the electricity transmission network $[1,3]$.

The author is considering the issue of granting access rights to third parties, guaranteed by the directive $2003 / 54$ / EC, whether the connection to the transmission system applies. It examines the narrow meaning and negative impact on competition of the term "third party" and the differences between the terms "connection" and "access" generally accepted by the European Court of Human Rights. He also noted that the judgment should not be interpreted as a universal restriction for connecting new consumers to distribution systems.

The paper [4] shows that Zambia has energy resources that can provide basic energy services to more than 16 million citizens. Despite this, only $25 \%$ of the Zambian population has access to electricity and clean home, which in turn leads to extensive use of wood energy. In addition, the greatest potential for renewable energy production in the country comes from solar and hydropower.

In the article "MNEs' Legitimacy Strategiesgies-the role of Institutional Distance in Sub-Saharan Africa: the State of Electricity", published in November 2015, the author [6] noted that epochal changes are taking place in sub-Saharan Africa, which may be becoming a new frontier for business.

Multinational enterprises (MPs) wishing to work in it should adopt a legalization strategy that demonstrates their commitment to the social and long-term local context. This will be a vital approach in promoting access to electricity for the local population.

In this case, heterogeneity to the sensitivity of household prices is allowed. 18,671 households in the national sample were used for the assessment. In turn, this case shows the general problem of lack of data in research.

Examines the investments needed to achieve universal access to electricity in subSaharan Africa, as well as the additional operating and other costs associated with these investments. It also examines the drivers of these costs, examining hundreds of scenarios that combine alternative assumptions about the level of targeted services, population growth, urbanization, industrial demand, and the cost of technology. The annual investment 
required to achieve universal access ranges from an average of 14.5 USS billion per year [8].

In [9], data from the national sample study of household electricity consumption in India are used. This article examines the issue of ensuring access to affordable services in the electric power industry within the framework of the energy sector reform program conducted in the state of Orissa (India). To make a comparative picture of Orissa with a state that does not follow the path of a World Bank-inspired restructuring from the energy sector we use similar data for West Bengal. According to the author's research, the increased availability of electricity for $60 \%$ of the population remains unchanged, and for poor households, the load on electricity is significantly high.

Despite the fact that those living in developed countries consider electricity production and efficiency reasons, the United Nations Development Programme (UNDP) estimates that 1.4 billion people do not have access to electricity. Bonvoisin also added this information to his article in 2015 [10]. The most developed countries can be described as "low-energy countries" and say that more than $70 \%$ of the population of sub-Saharan African countries cannot access electricity.

The author in the article [11] "On the regulation and control of EU integration in the liberalized electricity sector" reports that the electricity sector is a typical grid industry consisting of four closely interrelated vertical stages. After liberalization in Europe in the 1990 s, the sector saw a surge in mergers, which were reviewed by the European Commission.

The paper [12] shows that the proportion of the population living in urban areas, or urbanization, is both an important demographic, socio-economic phenomenon, and a popular explanatory variable in the models of energy and electricity consumption at the macro level and related carbon emissions.

The author of the article [13] writes that despite the increasingly important use of impact assessments for electrification activities, geographical distribution, such assessments are given little attention. This is because cultural and regional differences limit the ability to transfer results between regions.

However, this determines that the cost of achieving this goal is very high. In his work, he provided experimental data on identified payment readiness (WTP) for three types of off-grid solar power devices, which showed the willingness of the population to spend a significant portion of energy costs to households.

Table 1. Statistical data on the production and consumption of electricity in Kazakhstan for 19922013 (Source: developed by the authors based on the materials of Internet resources).

\begin{tabular}{|c|c|c|c|c|c|}
\hline year & production & consumption & year & production & consumption \\
\hline 1992 & 79.00 & 83.00 & 2003 & 60.00 & 53.00 \\
\hline 1993 & 74.00 & 79.0 & 2004 & 63.00 & 54.00 \\
\hline 1994 & 63.00 & 60.00 & 2005 & 64.00 & 57.00 \\
\hline 1995 & 63.00 & 59.00 & 2006 & 68.00 & 61.00 \\
\hline 1996 & 56.00 & 52.00 & 2007 & 72.00 & 65.00 \\
\hline 1997 & 49.00 & 45.00 & 2008 & 76.00 & 69.00 \\
\hline 1998 & 47.00 & 42.00 & 2009 & 74.00 & 67.00 \\
\hline 1999 & 45.00 & 40.00 & 2010 & 78.00 & 73.00 \\
\hline 2000 & 49.00 & 44.00 & 2011 & 2011 & 82.00 \\
\hline 2001 & 54.00 & 49.00 & 2012 & 90.00 & 78.00 \\
\hline 2002 & 55.00 & 50.0 & 2013 & 88.00 & 82.00 \\
\hline
\end{tabular}




\section{Conclusion}

From the above, it can be concluded that the role of private project finance, equity, and commercial debt, is limited. In addition, there is still not enough to meet the agreed energy supply and energy delivery targets. These countries have noticeable low economic productivity with high demographic growth and private sector development is needed to ensure sustainable energy access for all residents of the country. The national budget and traditional models of community and network development are not sufficient to cover a large number of people served. Therefore, the energy sector needs other approaches to attract investment in the private sector.

\section{References}

1. L. Brant, L. Sidney, Revisiting STIRPAT for Disaggregated Population and Consumption-Related Environmental Impacts 31(5), 317-343 (2010)

2. A. Bello, Electricity Pricing System and Performance of Power Sector in Sub-Saharan Africa (2016)

3. A. Kotlowski, Utilities Law Review 17(3) (2009)

4. L. Martin, Accelerating Energy Access Through Public-Private Partnership Investment in Zambia (2018)

5. J. Bonan, S. Pareglio, M. Tavoni, FEEM WP 96 (2014)

6. M. D'Amelio, P. Garrone, L. Piscitello, MNEs' Legitimation Strategies and the Role of Institutional Distance in Sub-Saharan Africa: The Case of Electricity Provision (2015)

7. Zhang Fan, World Bank Policy Research Working Paper 5831 (2011)

8. C. Nicolas, B. Rozenberg, T. Peralta-Quirós, World Bank Policy Research Working Paper 8747 (2019)

9. M.Z. Siddiqui, Household's Access to and Affordability of Electricity During Reforms: A Comparative Study of Orissa and West Bengal (2004)

10. M. Bonvoisin, Hydropower in Sub-Saharan Africa: Making Energy and Development Possible (2015)

11. A. Christiansen, Regulation and EU Merger Control in the Liberalised Electricity Sector doi.org/10.2139/87055

12. L. Brant., L. Sidney, Global Environ. Change 24, 42-51 (2013) doi.org/10.1016/j.gloenvcha.2013.11.013

13. D.A.J. Jaeger, P. Bayer, R. Kennedy, et al, A Systematic Review of Geographic Bias in Impact Evaluations of Electricity (2019)

14. S. Gulyani, J. Darby, World Bank Policy Research Working Paper 5388 (2010)

15. M. Grimm, L. Lenz, J. Peters, M.Sievert, IZA Discussion Paper 10427, https://ssrn.com/abstract=2889673 